DEPARTMENT OF

ECONOMICS

\title{
Valuing Changes in Forest Biodiversity
}

Mikołaj Czajkowski

Małgorzata Buszko-Briggs

Nick Hanley

Stirling Economics Discussion Paper 2008-17

August 2008

Online at http://www.economics.stir.ac.uk 


\title{
Valuing Changes in Forest Biodiversity
}

Mikołaj Czajkowski ${ }^{1}$, Małgorzata Buszko-Briggs ${ }^{2}$, Nick Hanley ${ }^{3}$

2008-08-16

\begin{abstract}
The paper offers an innovative approach to valuation of biodiversity. Instead of the prevailing approach of using only one indicator of biodiversity (usually number of species) we provide evidence that it is possible to provide attributes describing complex characteristics of biodiversity based on sound ecological knowledge. We argue that our approach managed to value the multi-level changes in the biological diversity, by using the attributes which described structural, species and functional diversity at the same time. Our study shows that it even complex indicators of multi-level biodiversity might be successfully communicated to respondents in a comprehensible and meaningful way. The empirical application of the method is provided based on a choice experiment study conducted in Białowieża Forest, Poland. The results underline the importance to use multilevel indicators and question validity of only species-level indicators. Interestingly, the respondents appreciated passive protection regimes, resulting in preservation of natural ecological processes. In addition, the respondents seemed to be concerned by means, and not only the results of protection programmes. Finally, some conclusions for future applications and policy making are drawn.
\end{abstract}

Keywords: Biodiversity; Forests; Valuation; Choice Experiment

\footnotetext{
${ }^{1}$ University of Warsaw, Warsaw Ecological Economics Center. Corresponding author. Email: miq@wne.uw.edu.pl

${ }^{2}$ Forest Research Institute, Warsaw

${ }^{3}$ University of Stirling, Department of Economics
} 


\section{Introduction}

As the biodiversity plays a critical role in overall sustainable development and poverty eradication (WSSD, 2002), and is essential to human well-being, livelihood and cultural integrity, it is becoming constantly better recognized, ever since its introduction in 1992 at the Earth Summit (CBD, 1992). However, biodiversity is under threat and there are signs that it is being dramatically changed and reduced. Biodiversity loss is characterized by the decrease in abundance and distribution of species, fragmentation of habitats, as well as distortion of habitat quality. There have been many attempts both to measure and value 'the biodiversity'. The pace has yet increased since OECD (2001) underlined the necessity for such studies and drew the list of their potential applications. The Convention on Biological Diversity (CBD) encouraged parties to take into account economic valuation in the development of relevant incentive measures for biodiversity conservation (CBD, 1998). It is particularly important for reaching the CBD 2010 Targets of halting loss of biodiversity.

Economists can indeed help measure the value of biodiversity, many of the previous studies, however, faced the two major problems. Firstly, it remains not an obvious choice to select a proper, quantifiable indicator or indicators of biodiversity. Secondly - even the best indicators from the ecologist's perspective may be not understandable to general public and hence improper for nonmarket valuation purposes. Without meaningful communication of them (and thus the entire concept of biodiversity) the values obtained need not be directly related to changes in biodiversity levels at stake. 


\subsection{Valuing biodiversity - the challenge}

Biological diversity means the variability among living organisms, and the ecological complexes of which they are part; this includes diversity within species, between species and of ecosystems (CBD, 1992). There are many approaches to defining the area on which biodiversity should be compared: from point diversity (homogenous habitat), through alpha (within habitat) and gamma (landscape scale), to epsilon diversity (regional, large biogeographic areas). Other levels of differentiation involve pattern, beta, and delta diversity (Whittaker, 1977).

Species level diversity is the most commonly used for practical purposes. It must be noted however that it does not reflect all the information necessary for the full description of biological diversity. What's more, this approach is not necessarily the most useful for assessing human impacts on biodiversity and its implications for ecosystem productivity, functioning and resilience. Last but not the least, species level of diversity assessment might on the one hand be easily explained to general public, but on the other it incorporates additional difficulties, since human values placed on species need not reflect the significance of that species for biodiversity. There exists substantial body of literature devoted to 'cuteness' concept of particular species and the existence of so called 'flagship species' or 'charismatic species' (May, 1995). People simply tend to place higher values on well recognized, high-profile species - usually impressive predators or species linked to local identity (Noss, 1990). Since economic values are by definition anthropogenic this relationship is understandable, however it causes estimation of biodiversity value based on species level 
more difficult, because the species highly valued are not necessarily the ones, which are the most important for the biodiversity - keystone species.

There have been some attempts to create a concept of ecologically important species that could easily be communicated to general public, such as ecological indicator and umbrella species, or concepts based on rarity. It is still, however, not clear to what extent the complicated relationship within ecosystem can be meaningfully explained and understood by the general public, which is usually the target of stated preference valuation techniques (Barbier, 2007; Christie, 2001; Heal et al., 2005).

There seem to exist no simple ways to communicate biodiversity and its changes to members of the public, nor an established framework for valuing biological variety. Number of species is considered a good starting point, it needs however to be reinforced with other attributes, such as existence of natural processes and specific habitats within the ecosystem. This paper reports an attempt to identify meaningful measures of full complexity and nature of biodiversity and utilizing these measures to value changes in biodiversity.

\subsection{The previous studies}

There seem to have been many valuation studies aiming at estimating the value of biodiversity. Following Pearce (2001) is must be noted however, that what most of these studies indeed valued was biological resources themselves rather than variety of life (biodiversity). This distinction, made clear by Nunes and Van den Bergh (2001), allows to categorise studies to those valuing particular biological resources, such as genes, species, habitats or ecosystems existence, and those valuing biological diversity of these resources. We refer the reader to Nijkamp et al. (forthcoming), Christie et al. (2004), Greensense (2003), 
Nunes et al. (2003) and Nunes and van den Bergh (2001) for the detailed review of these studies, and summarise the most common approaches below.

Valuation studies of biological resources are quite common in the literature. ${ }^{4}$ Use value of genetic diversity have been usually estimated utilising market based methods, such as inputs for production function of pharmaceutical, agricultural and chemical products (e.g. bioprospecting). On the species level of biological diversity, there have been numerous studies using stated preference techniques for assessing use and non-use values of particular species (including non-use existence value). Valuation of natural areas, such as terrestrial, coastal and wetland habitats, have been conducted in twofold: using travel cost method for estimating lower bound, recreational (use) value only, and utilising stated preference methods, such as contingent valuation or choice experiments, for existence or availability of such natural areas and changes in their quality. Finally, there have been only a few studies valuing ecosystem functions and services. This is probably the most challenging task for stated preference techniques, because the complexity of the relationships between ecosystem characteristics and level of services provided is very difficult to explain and convey in a short $\mathrm{CV}$ or CE survey. For this reason it is more usual to apply other valuation techniques, such as averting behaviour, replacement cost and production function to estimate the value of such services as waste assimilation, flood control or water quality.

Another and more useful in this case body of applied valuation literature focuses on valuation of biological diversity. Two approaches can be identified - studies eliciting WTP for policies aiming to, or resulting in, particular biodiversity increase, and studies trying to value changes in sets of components or indicators, that describe biological diversity of an area.

\footnotetext{
${ }^{4}$ Christie et al. (2004) make it clear that what these studies usually aim to value is biological resource itself rather than its biological diversity. For this reason they are not directly useful for estimating value of biodiversity, even if described changes in environmental resources indeed cause changes in its biodiversity.
} 
Good examples of the first, top-down approach are Garrod and Willis (1997) who estimated non-use values for remote upland coniferous forests in the UK, Hanley et al. (2002) who examined public preferences for biodiversity across a range of woodland types, Pouta et al. (2000) and Li et al. (2004) who elicited preferences for the extension of Natura 2000 area in Finland and Horne et al. (2005) who examined preferences for management options and resulting expected characteristics of the privately owned forests. Even though this approach is relatively easier, because the improvement is provided as a part of a scenario, which could be the basis for a CV study, it has its drawbacks. First of all it might be difficult to predict how a particular program would influence biodiversity. Secondly, a program might consist of many elements, biodiversity being only one of them. In this case the respondent's WTP might be only partly reflecting utility from improvement of biodiversity and partly other reasons for implementing the programme. The shadow prices of separate attributes are usually indeterminable in CV studies.

Applications of the second, bottom-up approach were more seldom, and can be represented by studies of Christie et al. (2004; 2006) who skilfully identified a meaningful set of attributes to describe variation in the biological diversity of agricultural landscape. The attributes involved well recognised wild species, not commonly known endangered species, quality of habitats and ecosystem functions (only those directly influencing humans). The authors argue, that in this case the selected set of attributes well describes biological diversity and remains meaningful to the respondents.

There seems to be the need for developing the latter approach. Since most of respondents are not familiar with the term 'biological diversity', the best way is to describe it with a set of attributes that are based on sound ecological knowledge and at the same time understandable 
to general public. ${ }^{5}$ A set of attributes describing biodiversity might often be site specific, however some general guidelines might be established through a process of empirical testing of different approaches. It seems interesting to test if the approach prevalent in the literature using number of species as the only indicator of biodiversity changes - is indeed the only approach which might be comprehensible to respondents, or at least if it is the most important one.

The main purpose of this paper is to extend the approach initialized by Christie et al. (2004) by describing biodiversity using carefully chosen attributes that would be both scientifically sound and comprehensible to the respondents. Our approach aimed to describe structural, species and functional diversity simultaneously and communicate these difficult issues to the respondents. It was also designed in a way allowing for conclusions if the way of providing ecological changes matters to the general public. Finally it provides evidence on valuation of biological diversity in an Eastern European country.

\section{The study}

The aim of this study was to implement the above formulations, estimating the value of changes in forest biological diversity of the Białowieża Forest, Poland as a case study. The use of stated preference techniques was selected in order to estimate full (use and non-use) value of changes in the biodiversity of the Białowieża Forest. We've decided to utilise choice experiment in order to be able to compare relative importance of the attributes separately.

\footnotetext{
${ }^{5}$ It is important, however, to keep the number of attributes reasonably small for the practical reasons of CE implementation.
} 


\subsection{Site selection}

$65 \%$ of biodiversity resources in Poland are located in forests, which cover roughly $30 \%$ of the country's surface (Rykowski, 2005). One of the most recognised and ecologically valuable forests in Poland is the Białowieża Forest, which despite some visible signs of human activity is still commonly considered the last natural lowland forest in temperate climate Europe. It is especially valuable for its natural dynamics of forest ecosystems as well as richness of species, and ecological structures and functions. For these reasons it was selected to be the site of our valuation study.

Some authors suggest that the protection goal of the highest priority should be a protection of all forms of variability of the Białowieża Forest, including landscape, habitats and their components, species, as well as biological and ecological processes (Faliński, 1992). This allows for long-term observation of flora dynamics: succession and regression, fluctuation, degeneration and regeneration, as well as seasonal changes. Most transformed and actively managed temperate forests in Poland and in Europe do now allow for valuable observations of all the above processes and this makes the Białowieża Forest unique.

Almost $40 \%$ of currently known species present in Poland (over 11000 ) can be found in the Białowieża Forest ${ }^{6}$. It is estimated that many fauna species are still undiscovered (Gutowski and Jaroszewicz, 2001). The forest habitats are characterised by the presence of a large volume of dead wood therefore many endangered species, dependent on this, are still present in the Białowieża Forest. One of the flagship endangered species that exists here is the

\footnotetext{
${ }^{6}$ The area of the Białowieża Forest is roughly 62000 ha, what accounts for only $0.02 \%$ of the territory of Poland.
} 
European Bison $(\dot{Z} u b r)$. The Białowieża Forest played an important role in this species restitution.

\subsection{Development of the questionnaire}

The authors of this paper identified proper attributes of biodiversity at the selected site based on sound ecological knowledge and ecological research results, which were conducted at the studied site over the last 50 years. A careful process of pretesting allowed for the valuation study that aims at estimating value of changes in forest biodiversity.

To properly describe the changes in biological diversity of the site the most important elements of biodiversity were identified with cooperation with biologists and ecologists and based on approaches present in the ecological literature (Christie et al., 2004). The entire list of attributes considered contained: familiar species of wildlife (rare and common), unfamiliar species of wildlife (rare and common), quality of habitat, ecosystem processes, ecosystem resilience, habitat for endangered and protected plant and animal species (red list), forest stand structure, landscape diversity, amount of dead wood, and others. Our approach consisted in trying to find the most important biodiversity attributes from the ecological perspective and then explain them to the respondents, thus making it possible to indirectly value biodiversity rather than elicit willingness to pay for the most well known or simply the most important attributes to the respondents, which need not necessarily correspond to the biodiversity improvements.

Through the careful process of pretesting and focus groups these attributes were merged and finally narrowed down to the 3 most important ones, at 3-4 levels and additionally - a cost 
attribute. The selected attributes well represented potential changes is the biodiversity and at the same time were understandable and possible to convey to the respondents.

The first attribute - natural ecological processes - represented natural dynamics of the Białowieża Forest. This illustrated natural changes of the forest's flora described above. Occurrence of these natural, not influenced by human activity (or management) processes allows for unique scientific observations of biodiversity changes and their meaning for ecosystem functioning and resilience. According to the specialists, and as explained in the questionnaire, the improvement in this attribute could be achieved by passive protection of a given percentage of the total area of the Białowieża Forest. Three possible levels of this attribute were: status quo - 16\%, partial improvement - 30\%, and substantial improvement$60 \%$ of the area to be passively protected.

Rare species of fauna and flora represented the second attribute. It was highlighted in the questionnaire, that this attribute represents not only known, but also yet unknown species. Examples of both flagship and less known species were given together with the information of yet unknown species and their dependence on protection. A short general explanation of the importance of different species to the ecosystem was provided. The possible levels of this attribute were: status quo - i.e. a decline threatening with total extinction, partial improvement - i.e. allowing to maintain the current standings and improvement of their quality, and substantial improvement - i.e. allowing to maintain the current standings as well as their expansion.

Ecosystem components was the attribute characterizing existence of biotopes and ecological niches, such as dead wood, natural ponds, streams, clearings etc. It was explained in the questionnaire that improvements in this attribute may be achieved by active protection of these components. This attribute could be important for respondents both for the existence of the components alone, as well as a proxy for better well-being of species inhabiting the forest. 
The possible levels of this attribute were: status quo - i.e. the lack of some components and decrease in the quality of the existing ones, minor improvement - regeneration of deteriorated components on $10 \%$ of the area, partial improvement - on $30 \%$, and substantial improvement - on $60 \%$ of the area.

The attribute levels, including status quo, were based on the present state of the Białowieża Forest and possible changes of management regime, which are currently considered by the policymakers and environmentalists. The last attribute was monetary, representing an increase in a compulsory tax to be paid for the following 10 years.

The questionnaire was administered face-to-face to the representative sample of adult Poles in order to discover preferences towards biodiversity (and its components) and test the approach we developed. It consisted of general information about the Białowieża Forest, its current situation and problems, detailed description of attributes, their possible levels, and their meaning for ecosystems, socio-demographical and environmental attitude questions. Some of the questions were designed and located within the survey to identify protest responses. The survey was accompanied by a set of auxiliary cards with diagrams and pictures, shown to the respondents for illustration of the discussed problems and better understanding of possible options.

\subsection{The experimental design}

The experimental design was prepared using fractional factorial design with blocking. Each respondent was presented with four choice sets, each of three alternatives. The first alternative (labelled) represented status quo option and there was no variance in its attribute levels (including cost). The second alternative was labelled 'extension of the national park' while 
the third 'other form of protection'. The levels of the attributes were random in the two latter alternatives.

The purpose of labelling alternatives was to test if the respondents are in fact indifferent to how biodiversity protection was achieved, as found by some studies (Christie et al., 2006). Currently the national park covers roughly only $16 \%$ of the area of the Białowieża, despite the 20-year-old struggle of NGOs and environmental organizations to extend it to the over entire area of the forest. It might seem reasonable that some of the respondents would like to see the national park extended. It was explained in the questionnaire, however, that 'extension of national park' and 'other form of protection' are in every respect the same and all the differences between the two alternatives are illustrated by the attribute levels given in the choice table. Focus groups and pretesting confirmed that this issue was understood by the respondents.

Finally there was an additional 'opt out' alternative, which was described as 'I don't want to pay anything at all'. Selecting this alternative together with other attitude questions allowed for protest response identification. The design consisted of 32 choice sets blocked into 8 questionnaire versions. An example of the choice card is given in Annex 1.

\section{The results}

The face-to-face surveys were conducted in June 2007 on a nationwide representative quota sample of adult Poles by a professional surveying company. There were a total of 400 surveys collected resulting in 1600 choice observations.

Protest zero responses were identified as those where the respondent (1) selected the 'don't want to pay at all' option and (2) showed typical protesting attitude in the debriefing 
questions $^{7}$ and (3) declared the changes in the forest biological diversity are important to him. A total of 387 out of 1600 such observations were removed from the sample.

The statistical analysis was started with a typical Conditional Multinomial Logit Model (MNL), conducting Hausman test, however, indicated violation of Irrelevance of Independent Alternatives (IIA) property of the model. For this reason a number of different model specifications were tried, such as: Error Components, Nested Logit, Heteroscedastic Extreme Value, Random Parameters Logit and Multinomial Probit, each of many possible functional forms. These alternative approaches were compared using Vuong test (Vuong, 1989) and Clarke's distribution free test (Clarke, 2003; 2007). Where necessary tests were corrected for different numbers of estimated coefficients using Schwarz's (1978) Bayesian information criterion. The tests indicated the Nested Logit Model with normalization of the scale parameter at the top level of the tree to outperform other models.

The nested logit approach is an extension of the multinomial (conditional) logit model in which individuals are assumed to make a choice among $J$ alternatives in a choice set, however it allows for a possibility of different variances of the random error terms $\left(\varepsilon_{j}\right)$ across groups of alternatives and for similarities of random terms across alternatives thus allowing for some amount of correlation (non-zero and varying covariances of pairs of alternatives).

Following Greene (2007), Hensher et al. (2005), and Hensher and Greene (2002) the individual's $i$ utility function resulting from choosing alternative $j$ may be formalized as:

$$
U_{i, j}=\boldsymbol{\beta}^{\prime} \mathbf{x}_{i, j}+\varepsilon_{i, j}
$$

\footnotetext{
${ }^{7}$ Such as: 'polluters should pay', 'I'm against any additional taxes', 'I don't believe the money would be used as stated' etc.
} 
, where $\boldsymbol{\beta}$ is the parameter vector and $\mathbf{x}$ is the individual and alternative specific vector of characteristics of the choice. The individual specific random terms $\varepsilon_{i, j}$ are assumed to be identical and independently distributed with an extreme value distribution. Under these assumptions the probability that individual $i$ chooses the alternative $j$ of the available $J$ alternatives in the choice set becomes:

$$
\operatorname{Pr}\left(\underset{q \neq j}{\forall} U_{i, j}>U_{i, q}\right)=\frac{\exp \left(\boldsymbol{\beta}^{\prime} \mathbf{x}_{i, j}\right)}{\sum_{q=1}^{J_{i}} \exp \left(\boldsymbol{\beta}^{\prime} \mathbf{x}_{i, q}\right)}
$$

The nested logit model may be illustrated using a hierarchical choice, where individual chooses between groups of alternatives first, and between alternatives (or their groups) in a chosen group later. This way variances of random components may be different across alternatives, because they are composed of the random components specific to the entire group and random components specific to the alternative in the group. Formally, for a twolevel nested logit, the probability of choosing a particular alternative in a group (branch) becomes:

$$
\operatorname{Pr}\left(\forall_{q \neq j} U_{i, j \mid b}>U_{i, q \mid b}\right)=\frac{\exp \left(\boldsymbol{\beta}^{\prime} \mathbf{x}_{i, j \mid b}\right)}{\sum_{q=1}^{J_{i, j}} \exp \left(\boldsymbol{\beta}^{\prime} \mathbf{x}_{i, q \mid b}\right)}=\frac{\exp \left(\boldsymbol{\beta}^{\prime} \mathbf{x}_{i, j \mid b}\right)}{\exp \left(\log \left(\sum_{q \mid b}^{J_{i, j}} \exp \left(\boldsymbol{\beta}^{\prime} \mathbf{x}_{i, q \mid b}\right)\right)\right)}
$$

, and the probability of choosing a particular branch is given as: 


$$
\operatorname{Pr}\left(\forall_{s \neq b} U_{b}>U_{s}\right)=\frac{\exp \left(\boldsymbol{\alpha}^{\prime} \mathbf{y}_{b}+\tau_{b}\left(\log \left(\sum_{q \mid b}^{J_{i, j}} \exp \left(\boldsymbol{\beta}^{\prime} \mathbf{x}_{i, q \mid b}\right)\right)\right)\right.}{\exp \sum_{s=1}^{B_{i}} \exp \left(\boldsymbol{\alpha}^{\prime} \mathbf{y}_{s}\right)}
$$

, where $\boldsymbol{\alpha}$ and $\mathbf{y}$ are vectors of parameters and characteristics of branch choice respectively, and $\log \left(\sum_{q \mid b}^{J_{i, j}} \exp \left(\boldsymbol{\beta}^{\prime} \mathbf{x}_{i, q \mid b}\right)\right)$ is the inclusive value for branch $b$.

For the above two-level specification of the model the unconditional probability of observed choice becomes:

$$
\operatorname{Pr}\left(\underset{t \neq j}{\forall} U_{i, j}>U_{i, t}\right)=\operatorname{Pr}\left(\underset{q \neq j}{\forall} U_{i, j \mid b}>U_{i, q \mid b}\right) \times \operatorname{Pr}\left(\underset{s \neq b}{\forall} U_{b}>U_{s}\right)
$$

By allowing for the parameter $\tau \neq 1$ we get 2-level nested logit model, in which each alternative level random term is a composition of an error term specific for the alternative and the particular group of alternatives. This allows to account for differences in random components' variance and some level of correlation between alternatives while keeping a closed-form model structure.

The estimated nested logit model results are summarized in Table 1. The explanatory variables are dummies representing different possible improvements in the levels of the attributes, thus allowing for nonlinear marginal utilities. The variables represent partial and substantial improvement in the protection of the natural processes, improvement in the 'Rare 
species of fauna and flora ${ }^{, 8}$, and minor, partial, and substantial improvement in the quality of ecosystem components. PARK is a dummy representing the alternative specific constant for the labelled alternative 'extension of the national park' and Cost is the monetary variable measured in PLN.

Table 1. The Nested Logit Model

\begin{tabular}{|llll|}
\hline Variable & Coefficient & Standard Error & $p$-value \\
\hline $\begin{array}{l}\text { Natural Ecological Processes } \\
\text { (1-level improvement) }\end{array}$ & $0.28213^{* * *}$ & 0.09479154 & 0.0029 \\
\hline $\begin{array}{l}\text { Natural Ecological Processes } \\
\text { (2-level improvement) }\end{array}$ & $0.39521^{* * *}$ & 0.12019442 & 0.0010 \\
\hline $\begin{array}{l}\text { Rare Species } \\
\text { (improvement) }\end{array}$ & $0.19484^{* *}$ & 0.08553986 & 0.0227 \\
\hline $\begin{array}{l}\text { Ecosystem Components } \\
\text { (1-level improvement) }\end{array}$ & $0.26939^{* *}$ & 0.10561570 & 0.0108 \\
\hline $\begin{array}{l}\text { Ecosystem Components } \\
\text { (2-level improvement) }\end{array}$ & $0.30377^{* * *}$ & 0.10600908 & 0.0042 \\
\hline $\begin{array}{l}\text { Ecosystem Components } \\
\text { (3-level improvement) }\end{array}$ & $0.34398^{* * *}$ & 0.11899022 & 0.0038 \\
\hline $\begin{array}{l}\text { PARK } \\
\text { (alternative specific constant) }\end{array}$ & $0.34743^{* * *}$ & 0.06257316 & 0.0000 \\
\hline Cost & $-0.02126^{* * *}$ & 0.00299983 & 0.0000 \\
\hline
\end{tabular}

${ }^{* * *},{ }^{* *},{ }^{*}$ represent significance at $1 \%, 5 \%, 10 \%$ level respectively

Number of observations $\quad 1213$

Log likelihood function $\quad 1220.485$

Chi squared 204.0790

Degrees of freedom 9

$\operatorname{Pr}\left(\chi^{2}>\right.$ critical value $)=\quad 0.0000000$

\footnotetext{
${ }^{8}$ Because there was no statistical difference between 'partial' and 'substantial' improvement in the Rare Species attribute the improvement is represented jointly.

${ }^{9}$ ASC PARK was representing particular way of implementing the change - providing the changes in the form of national park extension.
} 
All the variables are significant at at least 3\% level and are of expected signs. The direct interpretation of the coefficients is difficult due to incorporated and unidentifiable scale parameter, however their relative values represent an increase in probability of choosing a particular alternative, if it included the variable. This interpretation allows to draw some conclusions. First of all, natural processes were relatively the most important component for the choices of the respondents. This is followed by the different levels of ecosystem components, which turn out more important than the rare species. This could be explained by the notion that the improvement in ecosystem components might result in an improvement in many rare species condition as well. Finally the alternative specific constant representing a particular way of implementing environmental change (extending the national park) turned out to be a significant variable. As noted before currently the national park covers roughly only $16 \%$ of the Białowieża Forest area and there is an ongoing debate whether the park should be extended to the whole area of the forest. It is worth noting that the variable PARK was significant independently from all the other attributes, and its interpretation may be the premium consumers get, when certain protection plan is implemented through the extension of the national park.

Implementing the approach suggested in Louviere et al. (2006) WTP values for each level of the attributes were calculated, with reference to the status quo level of each attribute. The results, given in EUR ${ }^{10}$, are summarized in Table 2. Standard errors were calculated using the Delta method.

\footnotetext{
${ }^{10}$ The values in EUR were calculated using the following exchange rate: 1 EUR $\approx 3.6$ PLN.
} 
Table 2. Implicit price estimates (EUR)

\begin{tabular}{|lccc|}
\hline \multicolumn{1}{|c}{ Variable } & Implicit price & Standard Error & p-value \\
\hline $\begin{array}{l}\text { Natural Ecological Processes } \\
\text { (1-level improvement) }\end{array}$ & $3.69^{* * *}$ & 1.0842 & 0.0007 \\
\hline $\begin{array}{l}\text { Natural Ecological Processes } \\
\text { (2-level improvement) }\end{array}$ & $5.16^{* * *}$ & 1.2913 & 0.0001 \\
\hline $\begin{array}{l}\text { Rare Species } \\
\text { (improvement) }\end{array}$ & $2.55^{* *}$ & 1.0215 & 0.0127 \\
\hline $\begin{array}{l}\text { Ecosystem Components } \\
\text { (1-level improvement) }\end{array}$ & $3.52^{* * *}$ & 1.2586 & 0.0052 \\
\hline $\begin{array}{l}\text { Ecosystem Components } \\
\text { (2-level improvement) }\end{array}$ & $3.97^{* * *}$ & 1.2335 & 0.0013 \\
\hline $\begin{array}{l}\text { Ecosystem Components } \\
(3-\text { level improvement) }\end{array}$ & $4.49^{* * *}$ & 1.3055 & 0.0006 \\
\hline $\begin{array}{l}\text { PARK } \\
\text { (alternative specific constant) }\end{array}$ & $4.54^{* * *}$ & 0.9468 & 0.0000 \\
\hline
\end{tabular}

$* * * * * *{ }^{*}$ represent significance at $1 \%, 5 \%, 10 \%$ level respectively

Wald Statistic

228.11752

$\operatorname{Pr}\left(\chi^{2}>\right.$ critical value $)=\quad 0.0000000$

\section{Discussion}

We applied a wide range of econometric modelling approaches and used a formal testing procedure to discriminate among them to find the model that would best explain respondents' choices. The model which turned out to be the best was the nested logit model. This is an interesting result in itself because it provides a comparison of performance of a broad range of models, and because it demonstrates that allowing for different levels of variance of random components between alternatives may outperform approaches accounting for preference heterogeneity. This result may be compared with Colombo et al. (2007), and Colombo and 
Hanley (2007) who find just the opposite and recommend including individual heterogeneity to improve modelling results.

Our results show that mean willingness to pay for the program of improving the biodiversity level in Białowieża Forest was 10-15 EUR depending on the scope of environmental change and the way of providing protection. These results are difficult to compare with other studies both because the site is unique and has little if any substitutes in Europe, and because the approach and attributes used were not implemented before. However, the range of the values seems reasonable in comparison with the similar programmes, and if the average income level is taken into account.

Some of the biodiversity valuation studies reported insufficient sensitivity of respondents' willingness to pay to scope of environmental change (eg. Veisten et al., 2004; Heberlein et al., 2005). In our study we observed that the difference between implicit prices of partial and substantial improvements in rare species attribute was not statistically significant. However, it is worth reminding that the difference between these attributes was only the expansion of current standings, in addition to maintaining and increasing their quality, represented by partial improvement. It appears that expansion of current standing did not associate with significantly larger utility levels of the respondents. Despite this, the implicit prices of both area of passive protection, and the amount of ecosystem components to be actively protected are increasing with the scope of the good. ${ }^{11,12}$ We believe that this provides evidence, that scope sensitivity can be indeed achieved in biodiversity valuation studies.

Some insight is provided by the comparison of implicit prices of the attributes, which reflect their relative importance for the respondents. It is interesting to find that the improvement in

\footnotetext{
${ }^{11}$ It was also observed that marginal utility of increasing levels of environmental improvements are decreasing. This remains in line with economic theory and may be explained by the status-quo reference level which was described as slow deterioration of environmental conditions.

${ }^{12}$ However, due to high standard errors of the estimates this evidence is rather weak.
} 
the area of protection of natural processes was found the most important. Since the unmanaged character of this forest is widely recognized, this result may be unique to the study site. None-the-less it illustrates that consumers can indeed appreciate natural processes happening without human interference. In other words, implementing passive protection regime can be understood and highly valued by general public, despite the prevailing active protection regimes in the country.

On the contrary, the implicit price of the improvement of conditions for rare species was found lower than implicit price of improvement of natural processes, and lower than improvements in ecosystem components. This result clearly illustrates that species alone are not necessarily a good proxy for measuring and valuing biodiversity. Our study shows that this statement is recognized not only by ecologists but also by general public, if accurate information about ecosystem functioning and importance is conveyed in an understandable way.

Incidentally, this result remains robust even in the light of the findings of Jacobsen et al. (2008) who recommend far higher willingness to pay if species were 'iconised', i.e. described using their names. In our study we both 'iconised' the species to be protected giving examples of flagship species (e.g. the Polish Bison) and less known species, as well as thoroughly explained that protection of the species would involve all rare species (well-known, lessknown and unknown), and the importance of the species and their protection to the ecosystem. Despite this, the results show that protection of species was recognised by the respondents to be less important contributor to the total biodiversity of the area.

Finally, the alternative specific constant representing providing environmental changes in a particular way (by an extension of a national park) turned out to be a significant variable. Currently the national park covers roughly only $16 \%$ of the area of Białowieża Forest and there is an ongoing debate whether the park should be extended to the whole area of the 
forest. It appears that the respondents had preferences for extending the national park per se, irrespectively of what the extension would really mean. ${ }^{13}$ This is because extension of the national park was not associated with any characteristics of the good that might have been excluded from the design. ${ }^{14}$ This results is contrary to the evidence found by Christie et al. (2006), however seems in line with the results of Jacobsen and Thorsen (forthcoming).

\section{Conclusions}

Our study offers some conclusions for future research and policy making, as well as implications for policy design and management. The approach we applied consisted in describing complex changes in the biodiversity using carefully selected set of attributes, and not, as more commonly applied in the literature, flagship species or changes in selected resources. On the other hand our approach did not simply elicit preferences over different management regimes that could lead to particular outcomes; as explained before this approach is in our view prone to difficulties in conveying the possible results of each policy meaningfully, and makes separation of different components of biodiversity impossible.

Therefore, our approach extends the technique initialized by Christie et al. (2006) by carefully selecting attributes describing characteristics of biodiversity of the area based on sound ecological knowledge, while at the same time remaining meaningful and understandable to general public. We argue that our approach managed to value the multi-level changes in the

\footnotetext{
${ }^{13}$ It's worth noting that the national parks in Poland may have different management regimes and protection goals; thus 'extending national park' does not associate with any specific set of actions or characteristics.

${ }^{14}$ It should be clearly stated that qualitative analysis conducted via focus groups and verbal protocols did not show any attributes associated with the extension of the national park. There was no embedding regarding 'extension of national park' since the respondents did not think that the extension itself would bring about any other changes than the ones described by the attributes; it was none-the-less strongly highlighted in the questionnaire that both alternative ways of protection would essentially mean the same changes to the environment described only by the given attributes.
} 
biological diversity of the Białowieża Forest. This was achieved by using the attributes which described structural, species and functional diversity at the same time.

These results provide valuable information for designing future policies of managing the Białowieża Forest. This is also interesting in the context of scarce evidence of biodiversity valuation in Eastern European countries (Żylicz, 2000; Bartczak et al., forthcoming). However, we argue that the results need not be site specific and may allow for some generalizations. In particular, the relative implicit prices of described components provide an insight that might be useful in designing any socially optimal policy. Interestingly, it was found that respondents may strongly prefer protection of natural ecological processes, at least for some environmentally valuable areas. This is equivalent to preferring passive protection regimes. What is more, improvements in the protection of rare species were not found to be the most important for the respondents. This provides illustration of potential inadequacy of more usual approach of using a number species as an indicator of biodiversity of an area. We believe that these results may be of a more general character and offers a guideline for future applications of biodiversity measurement or valuation.

Finally, our results show that the respondents may be concerned with the way in which an environmental change is provided, even if many approaches may result in the same environmental results. We have found that the respondents were concerned not only with achieving a certain biodiversity outcome but also with how this might be achieved. In other words, the way of protection itself might be an important constituent of the perceived value of an environmental protection policy. This should draw researchers' attention to the process of 'labelling' or 'selling' particular conservation programmes, in order to maximize social welfare. 


\section{Acknowledgements}

We wish to thank Tomasz Żylicz for his assistance with designing and conducting this study as well as invaluable comments. The funding of Polish Ministry of Science and Higher Education and the Foundation for Polish Science is greatly appreciated. 


\section{References}

Bartczak, A., Lindhjem, H., Navrud, S., Zandersen, M., and Żylicz, T., forthcoming. Valuing Forest Recreation on the National Level in a Transition Economy: The Case of Poland. Forest Policy and Economics.

CBD, 1992. Convention on Biological Diversity. Rio de Janeiro, Brazil.

CBD, 1998. Decision IV/10, Measures for Implementing the Convention on Biological Diversity. Convention on Biological Diversity, Bratislava.

Christie, M., Hanley, N., Warren, J., Murphy, K., Wright, R., and Hyde, T., 2006. Valuing the Diversity of Biodiversity. Ecological Economics, 58(2):304-317.

Christie, M., Warren, J., Hanley, N., Murphy, K., Wright, R., Hyde, T., and Lyons, N., 2004. Developing measures for valuing changes in biodiversity, Final Report. DEFRA, London.

Clarke, K.A., 2003. Nonparametric Model Discrimination in International Relations. The Journal of Conflict Resolution, 47(1):72-93.

Clarke, K.A., 2007. A Simple Distribution-Free Test for Nonnested Model Selection. Political Analysis, 15(3):347-363.

Colombo, S., and Hanley, N., 2007. Modelling preference heterogeneity in stated choice data for environmental goods: a comparison of random parameter, covariance heterogeneity and latent class logit models. In: European Association of Environmental and Resource Economists 15th Annual Conference, Thessaloniki, Greece.

Colombo, S., Calatrava-Requena, J., and Hanley, N., 2007. Testing Choice Experiment for Benefit Transfer with Preference Heterogeneity. American Journal of Agricultural Economics, 89(1):135-151.

Faliński, J.B., 1992. Cele Ochrony Przyrody w Puszczy Białowieskiej i Możliwości ich Osiagnięcia. In: Chrońmy przyrodę ojczysta, Warszawa, 16-41.

Garrod, G.D., and Willis, K.G., 1997. The Non-use Benefits of Enhancing Forest Biodiversity: A Contingent Ranking Study. Ecological Economics, 21:45-61.

Greene, W.H. (Ed.), 2007. Econometric Analysis. Prentice Hall, Upper Saddle River, NJ.

Greensense, 2003. Biodiversity. In: An Applied Integrated Environmental Impact Assessment Framework for the European Union, European Commission, Brussels.

Gutowski, J.M., and Jaroszewicz, B. (Ed.), 2001. Katalog Fauny Puszczy Białowieskiej. Instytut Badawczy Leśnictwa, Warszawa.

Hanley, N., Willis, K., Powe, N., and Anderson, M., 2002. Valuing the Benefits of Biodiversity in Forests. Centre for Research in Environmental Appraisal \& Management, University of Newcastle. 
Heberlein, T.A., Wilson, M.A., Bishop, R.C., and Schaeffer, N.C., 2005. Rethinking the scope test as a criterion for validity in contingent valuation. Journal of Environmental Economics and Management, 50(1):1-22.

Hensher, D.A., and Greene, W.H., 2002. Specification and estimation of the nested logit model: alternative normalisations. Transportation Research Part B: Methodological, 36(1):117.

Hensher, D.A., Rose, J.M., and Greene, W.H. (Ed.), 2005. Applied Choice Analysis: A Primer. Cambridge University Press, Cambridge.

Horne, P., Boxall, P.C., and Adamowicz, W.L., 2005. Multiple-use Management of Forest Recreation Sites: a Spatially Explicit Choice Experiment. Forest Ecology and Management, 207(1-2):189-199.

Jacobsen, J.B., and Thorsen, B.J., forthcoming. Where to Put a National Park and What to Put in it? An a Priori Study of the Willingness-To-Pay for Coming National Parks. working paper, ask for quoting permissions.

Jacobsen, J.B., Boiesen, J.H., Thorsen, B.J., and Strange, N., 2008. What's in a Name? The Use of Quantitative Measures Versus 'Iconised' Species when Valuing Biodiversity. Environmental and Resource Economics, 39(3):247-263.

Li, C.-Z., Kuuluvainen, J., Pouta, E., Rekola, M., and Tahvonen, O., 2004. Using Choice Experiments to Value the Natura 2000 Nature Conservation Programs in Finland. Environmental and Resource Economics, 29(3):361-374.

Louviere, J.J., Hensher, D.A., and Swait, J.D. (Ed.), 2006. Stated Choice Methods: Analysis and Applications. Cambridge University Press, Cambridge.

May, R.M., 1995. Conceptual Aspects of the Quantification of the Extent of Biological Diversity. In: Biodiversity: measurement and estimation., D.L. Hawksworth, ed., Chapman and Hall, London, 13-20.

Nijkamp, P., Vindigni, G., and Nunes, P.A.L.D., forthcoming. Economic valuation of biodiversity: A comparative study Ecological Economics.

Noss, R.F., 1990. Can we Maintain Biological and Ecological Integrity. Conservation Biology, 4:241-243.

Nunes, P.A.L.D., and Van den Bergh, J.C.J.M., 2001. Economic Valuation of Biodiversity: Sense or Nonsense? Ecological Economics, 39:203-222.

Nunes, P.A.L.D., Van den Bergh, J.C.J.M., and Nijkamp, P. (Ed.), 2003. The Ecological Economics of Biodiversity: Methods and Policy Applications. Edward Elgar Publishing Ltd

OECD, 2001. Valuation of Biodiversity Benefits: selected studies. Paris.

Pearce, D., 2001. Valuing Biological Diversity: Issues and Overview. In: Valuation of biodiversity benefits: Selected studies, OECD, ed., OECD, Paris. 
Pouta, E., Rekola, M., Kuuluvainen, J., Tahvonen, O., and C.-Z., L., 2000. Contingent Valuation of the Natura 2000 Nature Conservation Programme in Finland. Forestry, 73(2):119-128.

Rykowski, K. (Ed.), 2005. O Gospodarce Leśnej w Leśnych Kompleksach Promocyjnych. Sękocin Las, Warszawa.

Schwarz, G., 1978. Estimating the Dimension of a Model. The Annals of Statistics, 6(2):461464.

Veisten, K., Fredrik Hoen, H., Navrud, S., and Strand, J., 2004. Scope insensitivity in contingent valuation of complex environmental amenities. Journal of Environmental Management, 73(4):317-331.

Vuong, Q.H., 1989. Likelihood Ratio Tests for Model Selection and Non-nested Hypotheses. Econometrica, 57(2):307-333.

Whittaker, R.H., 1977. Evolution of Species Diversity in Land Communities. Evolutionary Biology, 10:1-67.

WSSD, 2002. World Summit on Sustainable Development. Johannesburg.

Żylicz, T. (Ed.), 2000. Costing Nature in a Transition Economy. Case Studies in Poland. Edward Elgar Publishing, Chelthenham. 


\begin{tabular}{|c|c|c|c|}
\hline \multicolumn{4}{|c|}{ Annex 1. Example of the choice card } \\
\hline & Option A: & Option B: & Option C: \\
\hline & Status Quo & $\begin{array}{l}\text { Extension of the } \\
\text { National Park }\end{array}$ & $\begin{array}{l}\text { Other Form of } \\
\text { Protection }\end{array}$ \\
\hline $\begin{array}{l}\text { Natural Ecological } \\
\text { Proceses }\end{array}$ & $\begin{array}{l}\text { no change - } \\
\text { protection of natural } \\
\text { ecological proceses at } 16 \% \\
\text { of the forest area }\end{array}$ & $\begin{array}{l}\text { no change - } \\
\text { protection of natural } \\
\text { ecological proceses at } 16 \% \\
\text { of the forest area }\end{array}$ & $\begin{array}{l}\text { no change - } \\
\text { protection of natural } \\
\text { ecological proceses at } 16 \% \\
\text { of the forest area }\end{array}$ \\
\hline $\begin{array}{l}\text { Rare Species of } \\
\text { Fauna and Flora }\end{array}$ & $\begin{array}{l}\text { no change - } \\
\text { decline threatening } \\
\text { extinction }\end{array}$ & $\begin{array}{l}\text { substantial } \\
\text { improvement - } \\
\text { better condition of current } \\
\text { standings and their } \\
\text { expansion }\end{array}$ & $\begin{array}{l}\text { partial improvement - } \\
\text { maintaining and better } \\
\text { condition of current } \\
\text { standings }\end{array}$ \\
\hline $\begin{array}{l}\text { Ecosystem } \\
\text { Components }\end{array}$ & $\begin{array}{l}\text { no change - } \\
\text { lack of some components } \\
\text { and decrease in quality of } \\
\text { the existing ones }\end{array}$ & $\begin{array}{l}\text { minor improvement - } \\
\text { regeneration of deteriorated } \\
\text { components on } 10 \% \text { of the } \\
\text { forest area }\end{array}$ & $\begin{array}{l}\text { partial improvement - } \\
\text { regeneration of deteriorated } \\
\text { components on } 30 \% \text { of the } \\
\text { forest area }\end{array}$ \\
\hline $\begin{array}{l}\text { Cost - your tax } \\
\text { increase (yearly) }\end{array}$ & $0 \mathrm{zł}$ & $50 \mathrm{zł}$ & $10 \mathrm{zł}$ \\
\hline CHOICE & $\square$ & $\square$ & $\square$ \\
\hline
\end{tabular}

